Research Article

\title{
Cooperative Innovation Behavior Based on Big Data
}

\author{
Guojun Ji, ${ }^{1}$ Muhong Yu $\left(\mathbb{D},{ }^{1}\right.$ and Kim Hua Tan ${ }^{2}$ \\ ${ }^{1}$ School of Management, Xiamen University, Xiamen 361005, Fujian, China \\ ${ }^{2}$ Nottingham University Business School, The University of Nottingham Jubilee Campus, Nottingham NG8 1BB, UK
}

Correspondence should be addressed to Muhong Yu; 9212533@qq.com

Received 11 December 2019; Revised 25 March 2020; Accepted 2 April 2020; Published 28 April 2020

Academic Editor: Emilio Gómez-Déniz

Copyright (c) 2020 Guojun Ji et al. This is an open access article distributed under the Creative Commons Attribution License, which permits unrestricted use, distribution, and reproduction in any medium, provided the original work is properly cited.

With the rapid change in technology, cooperative innovation based on data sharing has become an imminent tactic for enterprises to gain competitive advantages. This paper adopted a mixed method approach (case study-modelling-case study) to study firms' co-opetition behavior based on their data analytics capabilities for innovation. We show that firms favor cooperation among peers with same capabilities, i.e., when each firm's data level is comparable to their partners. We further establish that data transferability and incentive have high impact on cooperation decisions. Finally, we explain the evolution path of firms' cooperation decisions and discuss the best options for them to sustain long-term growth and competitiveness. The results provide a basis for firms to decide how best to utilize big data for collaborative innovation, so as to improve customers' product adoption and reduce costs.

\section{Introduction}

The rapid development of science and technology leads to the accelerated upgrading of products and services. Enterprises must break through the homogenization of products through innovation to maintain their survival and development. Shorter product life cycles, rising expenditures on $\mathrm{R} \& \mathrm{D}$, and saturated markets are some of the biggest challenges companies are facing [1]. However, the high risk and high investment of innovation make enterprises shy away from product innovation [2], and the complexity and uncertainty of product innovation make traditional enterprises worry about their limited resources and capabilities [3]. In this complex scenario, enterprises should not innovate in isolation, at least not in an effective way [4]. In order to overcome the limitations of a single enterprise, enterprises have to break through the organizational limitations and seek to cooperate with other enterprises in product innovation [5]. Cooperative innovation has become the rational choice of enterprises. Enterprises need to engage in cooperation to get access to other entities' resources and capabilities [6]. A growing literature supports the benefits of cooperative innovation [7-10]. Recent studies highlight the importance of information or knowledge sharing among supply chain enterprises in cooperative innovation. For example, enterprises with successful product innovation characterized by a higher degree of novelty usually use a wider range of knowledge sources to develop their products [11]. Nonetheless, a sufficient degree of absorptive capacity is required for effective learning in a collaborative agreement between firms [12]. A firm is in a better position to scan and utilize the external knowledge when their level of absorptive capacity is high [13], acquired through collaborative innovation networks, thereby increasing innovative capabilities.

In the era of digital economy, data resources become an important strategic resource for enterprises. Massive data utilization has changed the way of production and global supply chain [14]. Data-driven business operations have been the focus of many enterprises [15]. Many leading enterprises (such as IBM, Cisco, and Huawei) have gathered big data from their products and platforms to achieve competitive advantage and profit growth. Leveraging the value of big data will become the basis for competition for today's enterprises [16]. Hence, the ability of firms to aggregate, elaborate, and analyse the data is becoming a key competitive advantage [17]. Many researchers point out that big data can improve business performance [18], effectiveness in decision-making [19], the renewal of companies' intangible assets [20], higher customer satisfaction [21], and accelerating product/service innovation [22], for example, 
promote product upgrading by obtaining information related to existing products [23] and help enterprises in the early stages of product development to determine customer expectations of products [24]. In the information age, the connotation of "data" began to expand, text, image, audio, video communication, location, and others generated by information technology was incorporated into the concept of data [25]. In addition, big data may come from a variety of sources, especially outside of firms. To use data in a better way, it is necessary to share data with stakeholders [26].

On the other hand, externalities and hitchhiking often occur in the process of knowledge sharing [27]. Due to the asymmetry of the private information of the parties and the incompleteness of the cooperation contract, bilateral moral hazard exists objectively [28]. Members' speculative behavior leads to the failure of cooperative innovation [29]. From the standpoint of maximizing their own interests, each party of the cooperation takes the opportunistic behavior to reduce the investment of its own specific assets or weaken its own efforts, which makes it difficult to succeed in cooperative innovation, especially when there is a competitive relationship between the two parties of the cooperation. Under the limitation of resource, competitors seek for competitive advantages through appropriate resource sharing and reasonable benefit distribution, thus making competition and cooperation co-evolve, and finally forming a dual relationship of both competition and cooperation [30]. Due to the high time requirement of big data processing and the small proportion of valuable data [31], cooperative enterprises have to share data to improve the success rate of innovation. However, data sharing loses its unique right to data, and competitors' opportunism will cause great losses to the sharing party. How could firms better cooperate with others to enhance their innovation performance under the condition of sharing data? So far, little is available in literature to address this. This paper aims to study how big data capabilities affect cooperative behaviors and decisions among co-opetition firms.

In this paper we adopted a mixed method (case studymodelling-case study) to study the cooperative innovation behaviors based on big data. Firstly, we reviewed literature to provide the background of this study. After that, we use a real case study to explain the motivation and challenges of cooperation innovation based on big data and the importance of data analytics capabilities and incentive in decisionmaking. Then, a model is proposed to analyse the cooperation behaviour. Finally, a case study is conducted to verify the results obtained from the model.

\section{Literature Review}

2.1. Big Data and Innovation. Big data has received considerable attention from academics and practitioners in recent years as a new top trend [21, 32-34]. Prior literatures have made rich studies on innovation performance and the influence factors. Many researchers point out that big data makes significant influence on the firm's innovation. For example, big data could help firms acquire knowledge about purchase behavior and market trends $[22,32]$. With a large amount of available data, firms can quickly exploit new information to create and implement new knowledge and ideas [33]. Data variety helps firms view innovation problems from different perspectives, which enables them to develop new ideas better [34]. Compared with other big data characteristics, data velocity plays a more important role in improving firm innovation performance [35]. Real-time data can help firms quickly develop new ideas and convert them into innovative products before their competitors, so firms need to quickly utilize information from integrating and analysing big data to implement effective and efficient innovation [36]. The common finding from these studies is that the ability of firms to aggregate, elaborate, and analyse the data is becoming a key competitive advantage and resource [24, 37].

Based on this significant influence, some scholars paid attention to the management and incorporation of big data into innovation processes, known as big data analytics capability $[38,39]$. In general terms, the related studies have resulted into two development aspects. One of them is focused on tangible resources and infrastructure aspects, and the efficient data management is achieved by means of a more robust infrastructure adapted to the gigantic magnitudes of big data [38]. This requires the firms undertake the necessary investments to advance big data initiatives and generate the yield that was set [40]. The second line is associated with intangible resources and human aspects, which is often also referred to as knowledge-based capital [41]. For example, high levels of learning capacity enable the combination and validation of knowledge extracted from big data, rendering informed decision-making process [33]. Big data technologies potentially lower the absorption costs of external knowledge, i.e., the costs for identification, retrieval, and exploitation of information [42]. The adoption of datadriven decision-making was particularly high in larger firms and in firms with more skilled workers and a higher IT capital stock [43]. Furthermore, some empirical studies also proved the complementarity effects between investments in infrastructure and intangible capital [41, 44, 45]. In this context, the design and management of the big data capability is particularly relevant to the big data resources, which implies paying attention to two dimensions: tangible (available data volume and data variety) and intangible (data culture, knowledge, and skilled labour).

2.2. Cooperative Innovation. Cooperative innovation has increasingly attracted both researchers' and practitioners' attention as an appropriate solution to increased knowledge intensity and the ever-increasing cost of $R \& D$ that it becomes progressively difficult for an individual firm to stay creative and innovative in the long run [46]. Earlier studies increasingly highlight the importance of collaboration with different types of partners in enabling firms to develop innovative products particularly through accessing tacit knowledge [12]. In cooperative innovation, there are a lot of researches on cooperation between different enterprises types (see Table 1). In addition to utilizing internal resources, enterprises will cooperate with industry leaders, suppliers, 
TABle 1: Comparison of different cooperative partners.

\begin{tabular}{lcc}
\hline Perspectives & Main partner & Related literature \\
\hline & Supplier [49-51,61-63] & Krause et al., 2007; Tomlinson and Philip, 2010; Jean et al., 2014; Zehui et al., 2014; Clauss \\
et al., 2016; Wang et al., 2016
\end{tabular}

universities, and competitors. The most prominent partners for cooperation in the innovation process can be assigned to vertical (supplier and customer), horizontal (competitors), and institutional (universities and research institutes) sectors [47]. With respect to performance outcomes of these cooperation types, past research indicates that, cooperation is beneficial for a firm [48]. In the case of vertical cooperation, Tomlinson found evidence that the stronger the dyadic relations between vertical partners, the higher the innovation success [49]. This finding is in line with other studies that focused on innovating and cooperating throughout the supply chain $[50,51]$.

Besides vertical cooperation, working with competitors (horizontal cooperation) received more attention lately. For example, Peng et al. [52] as well as Luo et al. [53] acknowledged that cooperating with competitors enhances firm performance. In reference to these findings, two other studies showed that the success of innovations jointly developed with a competitor also improves the ability to build up trust with the partner $[54,55]$. With respect to institutional cooperation, Bozeman [56] as well as Vuola and Hameri [57] examined universities and research institutes as cooperation partners and found out that this kind of cooperation plays an important role for the development of technological innovations. As discussed above, past research acknowledges the importance of cooperation with suppliers, customers, and research institutes throughout the innovation process for achieving innovation success. Although there are many successful cases of cooperative innovation, the success rate of cooperative innovation is not high. For example, Reuer and Zollo conducted an empirical survey on 445 cooperation conducted by 262 enterprises in this period, and the results showed that the results of innovation cooperation were not satisfactory; only $15 \%$ were successful, $34 \%$ were unsuccessful, and 51\% were interrupted [58]. At the same time, De Man and Duysters reviewed and summarized previous relevant studies from both theoretical and empirical aspects and found that, in previous innovation cooperation, cooperation failure rate was as high as $50 \%-$ $60 \%$ [59]. The failure rate of innovation cooperation cases among Chinese enterprises is as high as 50\% [60]. The research results show that the advantages of cooperation always accompany the disadvantages.

Although there is no market competition between the two parties, the expected cooperation results may not be achieved. For example, in supply chain cooperation, both firms can achieve win-win via cartelization if and only if their contribution levels are Pareto matched [61]. Customer participation can reduce the risk and uncertainty of R\&D to the greatest extent, but it has different effects in different periods of new product development [7, 65, 66]. The enterprise initiative of participating in the university-enterprise cooperation should be improved, and the scientific research achievements from universities could not satisfy enterprise's demands due to laying stress on the theory excessively [67].The effect of government-firm cooperation is mainly influenced by relational trust [68]. On the other hand, cooperation with market competition, co-opetition strategy helps SMEs to develop their ability to effectively pursue technological innovations [70]. But information coming from competitors seems to have a negative influence on the degree of novelty of innovation [71].

These results indicated that the cooperative innovation behavior shows the dualism of competition and cooperation, the cooperative relationship of cooperative innovation is easy to break down, and the phenomenon of fighting alone is still common. From the perspective of research content, less studies considering about the role of big data capability in the cooperative innovation process. We aim to fill this research gap by posing the following relevant research question: how to achieve the stability of cooperative innovation relationship in the big data environment? However, the existence of spillovers increases the opportunism tendency of cooperative participants. It is important to consider the effects of knowledge spillovers and absorptive capacity in the cooperation innovation process.

2.3. Spillovers Effect and Absorptive Capacity. Knowledge spillovers are a pervasive phenomenon [73]. Firms are often able to obtain costless advantages from competitors' innovation activities [74]. According to the absorptive capacity hypothesis, the degree to which firms benefit from knowledge spillovers is largely dependent on investment in internal knowledge [75]. Many studies have demonstrated that firms that can effectively absorb external knowledge have better innovation performance [76]. Firms with high absorptive capacity could identify the value of external information and apply the information into innovation activities [77-79]. Analogously, firms with high absorption would be able to benefit more from knowledge spillovers than firms with low absorptive capacity [80]. While knowledge spillovers increase the diffusion speed of innovation, they also act as a disincentive to investment in innovation [74]. The disincentive of 
investment in $\mathrm{R} \& \mathrm{D}$ can be strong for innovators when knowledge spillovers are high [81], as firms aim to reduce research costs and may fear that opportunism will prevent them from actively searching for and sharing new knowledge $[74,82]$. Firms will limit their new investments in innovation if they see a decreased propensity to make exclusive use of the results of such investment $[83,84]$.

Considering big data as an important approach to help firms to maximize their innovation and efficiency $[4,37,39]$, it is important to understand how big data may impact on the firms' absorptive capacities $[85,86]$ as well as contribute to their success in promoting collaborative innovation. Academic research and reviews related absorptive as a capability that can impact positively innovation performances, but the influence of big data levels on absorptive capacity remains ambiguous. Therefore, this article studies the cooperative innovation in big data environment and explores the capability's influence mechanism. Taken together, our final research question is:How does the big data capability levels influence the cooperation intention and maintain a stable cooperative relationship? On this basis, suggestions are put forward to improve the innovation performance, which can provide reference for firms to make cooperative innovation decisions.

\section{Case Study}

Enterprise $\mathrm{S}$ is an agent of computer hardware based in Xiamen, China. Its business includes two aspects: selling hardware equipment of upstream manufacturers and providing hardware-related services to consumers. Enterprise $S$ has been established for five years, and now, it has 13 employees. Its operating income reached 20 million yuan in 2018, and it has entered a high-speed growth period. The upstream manufacturer of enterprise $\mathrm{S}$ is the industry leader, and its product technology level is very high. However, the upstream manufacturers mainly focus on designing and producing products and not directly dealing with end consumers. S serves as a missing link in the supply chain, i.e., selling and servicing manufacturers' products to end consumers. Through providing products to after-sales service, $\mathrm{S}$ collected huge customer data that are valuable for the upstream manufacturers. Due to the small size of enterprises, low capacity of big data, and fierce competition in the industry, there are many agents competing with $\mathrm{S}$ for the same product and service. According to statistics, there have been more than 200 agents in Xiamen in 2018. Hence, the upstream manufacturers use incentives (discount, access to resources, and technical support) to entice $S$ or its competitors to share data (of end users). In light of this, $S$ considering cooperation among its peers, however, data analytics capabilities could be a big issue (SMEs lack resources and capabilities of data analytics as compared to large firms).

In short, enterprises $S$ tried to use big data to improve product innovation and service but encountered many problems, as follows: (1) although $\mathrm{S}$ has a huge numbers of customers, the customers are in a wide range of industries and the collected data are not complete or large enough; (2) existing staff lack data analytics capabilities; (3) lack of trust among supply chain members as well as from the upstream manufacturers in terms of data sharing ( $S$ believes large manufacturers only interested in its customers' data).

In light of this, $\mathrm{S}$ tries to carry out cooperative innovation with its peers. The advantage of this is that they have data of different customers in different industries, which can make up for each other. Moreover, in the aspect of data analysis, cost allocation can be carried out through cooperation and joint establishment of research departments. However, data transferability and incentive have high impact on cooperation decisions. There are mistrust among partners as they are competitors in the same market too. In addition, data analytics capabilities among peers can have strong impact on the cooperation decisions.

\section{Model and Analysis}

4.1. Models. In the process of collaborative innovation, firms will display two strategies: competition and cooperation [87]. Competitors who are originally opposite to each other under the limitation of resources (such as exclusive customer data) seek for competitive advantages through appropriate resource sharing and reasonable profit distribution, so that competition and cooperation can co-evolve and form a dualistic relationship of both competition and cooperation.

Without loss of generality, we assume that each firm as a partner can be the $\mathrm{S}$ or $\mathrm{R}$. Cooperative innovation means that the firms invest in the data acquisition or the big data analysis, which ensures the acquired data knowledge could transfer into the final innovation results. The complete process of cooperation includes the joint participation of both sides. Big data capability is the data acquisition ability or/and the analysis ability. The willingness to share is the premise to ensure the smooth progress of data sharing.

Based on previous studies, the willingness and data capability of the firms, the data stock, and the transferability of data into knowledge are the key elements of data resources sharing in cooperative innovation.

Before presenting our model, we introduce some notations as follows:

$i$ : index of firms, $i=s, r$

$c_{i}$ : firm $i$ 'sinnovation investment for cooperative

$Q_{i}$ : firmi's existing data stock

$T$ : the marginal benefit when data are ultimately transformed into corporate income

$e_{i}$ : firm $i$ s innovation effort

$\varphi$ : sharer's effort level elastic coefficient-big data capacibility

$\mu$ : reciever's effort level elastic coefficient-big data capacibility

$\beta$ : cooperative innovation income distribution ratio for firm $s$

Based on Cobb-Douglas cooperative production \$ \$function model [88], the output yield function is assumed to be: 


$$
Y_{i}=T Q_{i} e_{s}^{\varphi} e_{r}^{\mu}+\theta
$$

where $\varphi$ and $\mu$ also suggest the ratio of changes in knowledge output during the entire acquisition and sharing process when $\mathrm{S}$ or $\mathrm{R}$ increases their efforts. $\theta$ means exogenous random variable that affects knowledge of cooperative production, which obeys a normal distribution with a mean of 0 and a variance of $\sigma^{2}$, that is, $\theta \sim N\left(0, \sigma^{2}\right)$.

Furthermore, we assume the effort is quadratic in the level of cost reduction. That is, $c_{i}$ has to be paid to achieve a cooperative innovation for firm $i$. The actual income of the $S$ is equal to the remuneration obtained minus the data sharing cost. Firm S's expected income function is as follows:

$$
\omega=V\left(\pi_{s}\right)-C .
$$

The maximized expected utility function of the other party is equivalent to the maximized deterministic equivalent income, and the expected utility function can be replaced by deterministic equivalent income:

$$
E(\text { sharer })=\beta T Q_{i} e_{s}^{\varphi} e_{r}^{\mu}-c_{s} .
$$

The actual income of the $\mathrm{R}$ is the data sharing output minus the remuneration paid to the $S$, and the expected utility function is

$$
E(\text { receiver })=(1-\beta) T Q_{i} e_{s}^{\varphi} e_{r}^{\mu}-c_{r} .
$$

Assume that the probability of "cooperative strategy" and "competitive strategy" adopted by the $\mathrm{S}$ is $p$ and $1-p$, respectively. The probability of the $R$ adopting "cooperative strategy" and "competitive strategy" is $q$ and $1-q$, respectively. $R$ refers to the benefits gained from the "cooperative strategy" adopted by one party and the "competitive strategy" adopted by the other party. This income indicates that the partner enterprise shares necessary data, information, and knowledge for the overall benefit, while the competitor uses opportunities to form or strengthen its own advantages without any sharing or investment. Therefore, the degree to which competitors can turn $\mathrm{R}$ into their own advantages depends on their own learning ability. Let the learning ability of enterprise be $x_{i} E$, respectively. Assume that each game is played between these two firms, but such a game will be repeated many times until the evolution of the game strategy is stable. It is assumed that, due to the differences in technology accumulation, knowledge stock, and cooperation preference, the game process of cooperative innovation is an asymmetric evolutionary game. The payment matrix of the evolutionary game is shown in the following Table 2.

The expected revenue of cooperation for the $S$ is

$$
E_{s 1}=q\left(\beta T\left(Q_{r}+Q_{s}\right) e_{s}^{\varphi} e_{r}^{\mu}-c_{s}\right)+(1-q)\left(T Q_{s} e_{s}^{\varphi}-c_{s}\right) .
$$

The expected revenue of competitive for the $S$ is

$$
E_{s 2}=q\left(T Q_{s}+x_{s} T Q_{r} e_{r}^{\mu}\right)+(1-q) T Q_{s} .
$$

The average revenue function of $S$ is

$$
E_{s}=p E_{s 1}+(1-p) E_{s 2} .
$$

The expected revenue of cooperation for the $\mathrm{R}$ is

$E_{r 1}=p\left((1-\beta) T\left(Q_{r}+Q_{s}\right) e_{s}^{\varphi} e_{r}^{\mu}-c_{r}\right)+(1-p)\left(T Q_{r} e_{r}^{\mu}-c_{r}\right)$.

The expected revenue of competitive for the $\mathrm{R}$ is

$$
E_{r 2}=p\left(T Q_{r}+x_{r} T Q_{s} e_{s}^{\varphi}\right)+(1-p) T Q_{r} .
$$

The average revenue function of $\mathrm{R}$ is

$$
E_{r}=q E_{r 1}+(1-q) E_{r 2} .
$$

Under the assumption of bounded rationality, enterprises choose cooperation, there must be cooperation revenue greater than competition revenue, and similarly, there must be competition revenue greater than cooperation revenue when they choose competition. Therefore, the cost needs to meet the following conditions:

$$
\begin{aligned}
& T Q_{s}\left(e_{s}^{\varphi}-1\right)<c_{s}<\beta T\left(Q_{r}+Q_{s}\right) e_{s}^{\varphi} e_{r}^{\mu}-T Q_{s}-x_{s} T Q_{r} e_{r}^{\mu}, \\
& T Q_{r}\left(e_{r}^{\mu}-1\right)<c_{r}<(1-\beta) T\left(Q_{r}+Q_{s}\right) e_{s}^{\varphi} e_{r}^{\mu}-T Q_{r}-x_{r} T Q_{s} e_{s}^{\varphi} .
\end{aligned}
$$

Next, we discuss equilibrium results through evolutionary analysis.

\section{Equilibrium Analysis}

5.1. Equilibrium Points. According to the revenue matrix, the replication dynamic equation of both sides can be obtained as follows:

$$
\begin{aligned}
& F(p)=\frac{\mathrm{d} p}{\mathrm{~d} t}=p\left(E_{s 1}-E_{s}\right), \\
& F(q)=\frac{\mathrm{d} q}{\mathrm{~d} t}=q\left(E_{r 1}-E_{r}\right) .
\end{aligned}
$$

And then, we get a two-dimensional dynamical system:

$$
\left\{\begin{array}{l}
F(p)=p(1-p)\left(E_{s 1}-E_{s 2}\right) \\
F(q)=q(1-q)\left(E_{r 1}-E_{r 2}\right) .
\end{array}\right.
$$

When $F(p)=0, \quad p^{*}=1, p^{*}=0$, and $q^{*}=\left(c_{s}-Q_{s}\right.$ $\left.\left(e_{s}^{\varphi}-1\right) T / T\left(Q_{s} e_{s}^{\varphi}\left(\beta e_{r}^{\mu}-1\right)-Q_{r}\left(e_{r}^{\mu} x_{s}-e_{s}^{\varphi} \beta\right)\right)\right)$. In the same way, when $F(q)=0, q^{*}=1, q^{*}=0$, and $p^{*}=\left(c_{r}-Q_{r}\left(e_{r}^{\mu}-\right.\right.$ $1) T / T\left(Q_{r} e_{r}^{\mu}\left(e_{s}^{\varphi}(1-\beta)-1\right)-Q_{s} e_{s}^{\varphi}\left(x_{r}-e_{r}^{\mu}(1-\beta)\right)\right)$. To simplify the problem, we can define the critical point as follows:

$$
p_{0}=\frac{c_{r}-Q_{r}\left(e_{r}^{\mu}-1\right) T}{T\left(Q_{r} e_{r}^{\mu}\left(e_{s}^{\varphi}(1-\beta)-1\right)-Q_{s} e_{s}^{\varphi}\left(x_{r}-e_{r}^{\mu}(1-\beta)\right)\right)},
$$

$$
q_{0}=\frac{c_{s}-Q_{s}\left(e_{s}^{\varphi}-1\right) T}{T\left(Q_{s} e_{s}^{\varphi}\left(\beta e_{r}^{\mu}-1\right)-Q_{r} e_{r}^{\mu}\left(x_{s}-e_{s}^{\varphi} \beta\right)\right)} .
$$


TABle 2: The payoff matrix of the coopetition game.

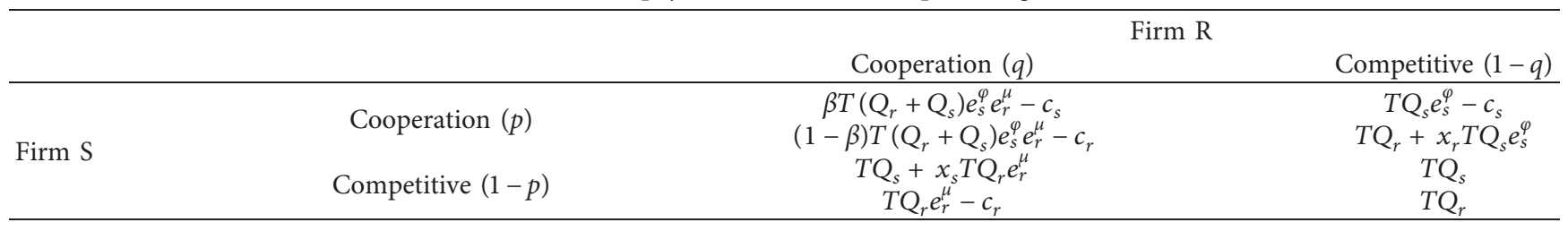

According to the expression, we can find that when $x_{s}<\left(\beta\left(Q_{r}+Q_{s}\right) e_{s}^{\varphi}-Q_{s} e_{s}^{\varphi} e_{r}^{-\mu} / Q_{r}\right)$ and $x_{r}<\left((1-\beta)\left(Q_{r}+\right.\right.$ $\left.\left.Q_{s}\right) e_{r}^{\mu}-Q_{r} e_{r}^{\mu} e_{s}^{-\varphi} / Q_{s}\right), 0<p_{0}<1,0<q_{0}<1$. So, $\left(p_{0}, q_{0}\right)$ is also an equilibrium solution.

Theorem 1. The equilibrium solution of the evolutionary game is $(0,0),(0,1),(1,0),(1,1)$, and $\left(p_{0}, q_{0}\right)$.

5.2. Stability Analysis of Equilibrium Solution. According to the system of differential equations proposed by Friedman [89], the stability of the equilibrium solution can be obtained by analysing the local stability of Jacobian matrix of the system. The Jacobian matrix of this dynamic system is

$$
J=\left[\begin{array}{ll}
\frac{\partial F(p)}{\partial p} & \frac{\partial F(p)}{\partial q} \\
\frac{\partial F(q)}{\partial p} & \frac{\partial F(q)}{\partial q}
\end{array}\right]
$$

If the equilibrium solution satisfies the following two conditions simultaneously, $\operatorname{tr} J=(\partial F(p) / \partial p)+(\partial F(q) /$ $\partial q)<0$ and $\operatorname{det} J=(\partial F(p) / \partial p) \times(\partial F(q) / \partial q)-(\partial F(p) /$ $\partial q) \times(\partial F(q) / \partial p)>0$. Then, the point is locally stable, and the equilibrium solution is an evolutionary stability strategy.

Situation 1. When $x_{s}>\left(\beta\left(Q_{r}+Q_{s}\right) e_{s}^{\varphi}-Q_{s} e_{s}^{\varphi} e_{r}^{-\mu} / Q_{r}\right)$ and $x_{r}>\left((1-\beta)\left(Q_{r}+Q_{s}\right) e_{r}^{\mu}-Q_{r} e_{r}^{\mu} e_{s}^{-\varphi} / Q_{s}\right)$, the equilibrium solution $(0,0)$ is the only stable strategy of the system, $(0,1)$ and $(1,0)$ are the saddle points, and $(1,1)$ is the labile point. The replicated dynamic diagrams for this situation are shown in Figure 1. This means that when both sides have strong learning ability, enterprises are more inclined to compete regardless of whether the other side chooses to cooperate or not. The reason for this is that, in the process of cooperation, it is impossible to predict whether the other party betrays or not, and a higher learning ability makes it easier for the strong side to choose betrayal. The risk of loss is higher than the benefit of cooperation, so both choose not to cooperate.

Situation 2. When $x_{s}<\left(\beta\left(Q_{r}+Q_{s}\right) e_{s}^{\varphi}-Q_{s} e_{s}^{\varphi} e_{r}^{-\mu} / Q_{r}\right)$ and $x_{r}<\left((1-\beta)\left(Q_{r}+Q_{s}\right) e_{r}^{\mu}-Q_{r} e_{r}^{\mu} e_{s}^{-\varphi} / Q_{s}\right)$.

(I) Dynamic process analysis for enterprise $\mathrm{S}$

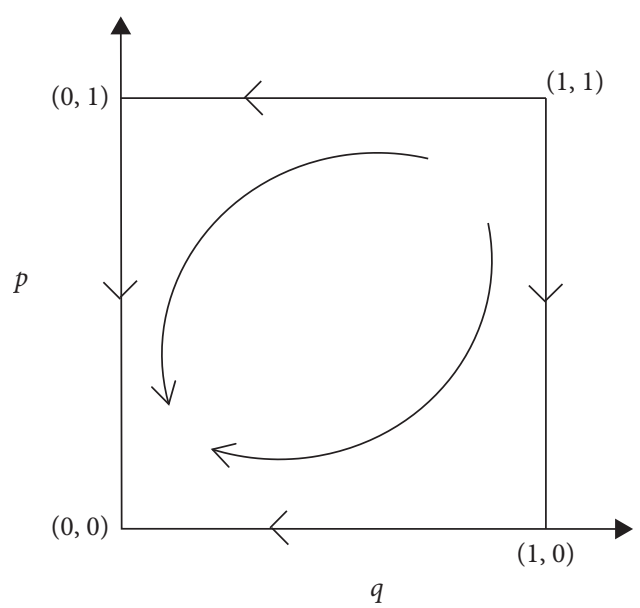

Figure 1: The replicated dynamic diagrams for Situation 1.

When $q=\left(c_{s}-Q_{s}\left(e_{s}^{\varphi}-1\right) T / T\left(Q_{s} e_{s}^{\varphi} \quad\left(\beta e_{r}^{\mu}-1\right)-\right.\right.$ $\left.\left.Q_{r} e_{r}^{\mu}\left(x_{s}-e_{s}^{\varphi} \beta\right)\right)\right)$, any value of $p$ guarantees a stable state. When $q<\left(c_{s}-Q_{s}\left(e_{s}^{\varphi}-1\right) T / T\left(Q_{s} e_{s}^{\varphi}\left(\beta e_{r}^{\mu}-1\right)-\right.\right.$ $\left.\left.Q_{r} e_{r}^{\mu}\left(x_{s}-e_{s}^{\varphi} \beta\right)\right)\right), p=0$ and $p=1$ are stable states and $p=0$ is the stable strategy. When $q>\left(c_{s}-Q_{s}\left(e_{s}^{\varphi}-\right.\right.$ $\left.1) T / T\left(Q_{s} e_{s}^{\varphi}\left(\beta e_{r}^{\mu}-1\right)-Q_{r} e_{r}^{\mu}\left(x_{s}-e_{s}^{\varphi} \beta\right)\right)\right), p=0$ and $p=1$ are stable states and $p=1$ is the stable strategy. Figure 2 describes the dynamic diagram and equilibrium state of $p$ under three values conditions.

(II) Dynamic process analysis for enterprise $\mathrm{R}$

When $p=\left(c_{r}-Q_{r}\left(e_{r}^{\mu}-1\right) T / T\left(Q_{r} e_{r}^{\mu}\left(e_{s}^{\varphi}(1-\beta)-\right.\right.\right.$ $\left.\left.1)-Q_{s} e_{s}^{\varphi}\left(x_{r}-e_{r}^{\mu}(1-\beta)\right)\right)\right)$, any value of $q$ guarantees a stable state. When $p>\left(c_{r}-Q_{r}\right.$ $\left(e_{r}^{\mu}-1\right) T / T\left(Q_{r} e_{r}^{\mu}\left(e_{s}^{\varphi}(1-\beta)-1\right)-Q_{s} e_{s}^{\varphi}\left(x_{r}-e_{r}^{\mu}\right.\right.$

$(1-\beta)))), q=0$ and $q=1$ are the stable states and $q=1$ is the stable strategy. When $p<\left(c_{r}-Q_{r}\left(e_{r}^{\mu}-\right.\right.$ 1)T/T $\left(Q_{r} e_{r}^{\mu}\left(e_{s}^{\varphi}(1-\beta)-1\right)-Q_{s} e_{s}^{\varphi}\left(x_{r}-e_{r}^{\mu} \quad(1-\right.\right.$ $\beta))), q=0$ and $q=1$ are the stable states and $p=0$ is the stable strategy. Figure 3 describes the dynamic diagram and equilibrium state of $q$ under three values conditions.

In this situation, both $(0,0)$ and $(1,1)$ are the stable strategy of the system, $\left(p_{0}, q_{0}\right)$ is the saddle point, and $(0,1)$ and $(1,0)$ are labile points. So the firms act together, one chooses to cooperate, and the other will cooperate. But the strategy that the system ultimately chooses to achieve equilibrium depends on the initial state of the system. The replicated dynamic diagram of the system is shown in Figure 4. 


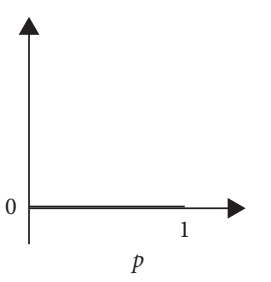

(a)

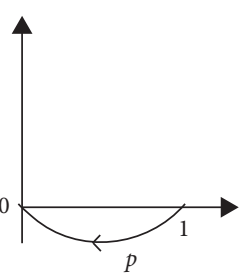

(b)

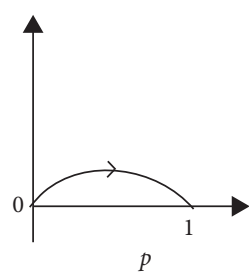

(c)

Figure 2: The replicated dynamic diagrams for firm S.

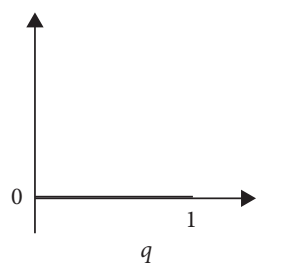

(a)

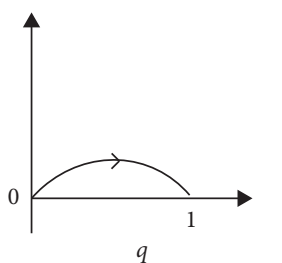

(b)

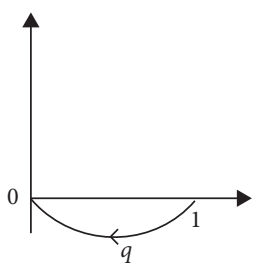

(c)

Figure 3: The replicated dynamic diagrams for firm R.

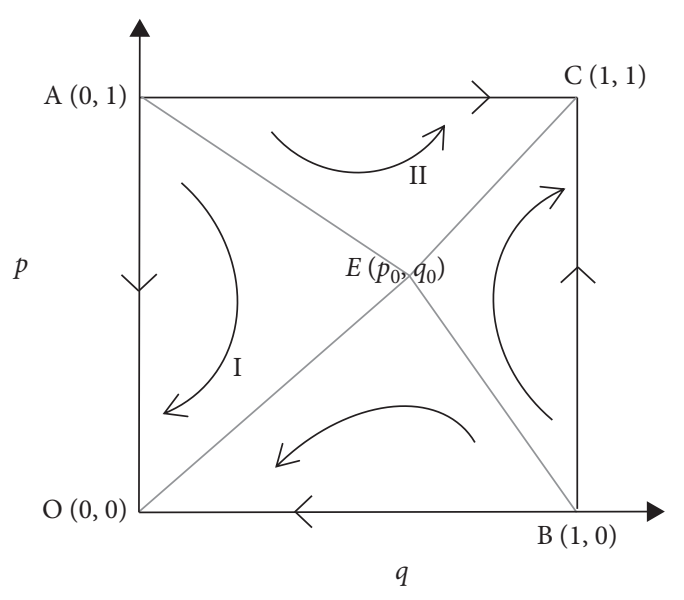

Figure 4: The replicated dynamic diagrams for system.

The result of this situation analysis indicates that when both enterprises have a low learning ability, both parties choose to cooperate and gain higher profits than they choose to steal big data knowledge. However, when one party chooses to betray, the loss of the other party is higher than the profit of cooperation, so both of them have to cooperate or choose the competitive strategy.

\section{Evolutionary Stability and Discussion}

According to the above equilibrium analysis results, $\mathrm{A}$ and $\mathrm{B}$ (in Figure 4) are labile points, $\mathrm{E}$ is the saddle point, and $\mathrm{O}$ and $\mathrm{C}$ are evolutionarily stable states (ESS). When the initial state of the game is in the regional OAEB, the strategies of enterprises will evolve to point $\mathrm{O}$ and eventually form a stable state where firms adopt competitive strategies. On the contrary, when the initial state of the game is in EACB, the strategy of the enterprise will evolve to point $\mathrm{C}$ and finally form a stable state where firms adopt cooperation strategy. This indicates that the area of OAEB and EACB will affect the evolution result of collaborative innovation, and the trust of firms' cooperation preference to each other will play a positive role in the evolution of cooperative innovation strategy. When $S_{\mathrm{OAEB}}=S_{\mathrm{EACB}}$, the probability of both sides adopting cooperation or competition strategy is equal; when $S_{\mathrm{OAEB}}>S_{\mathrm{EACB}}$, the probability of both sides adopting competition strategy is higher than cooperation; when $S_{\mathrm{OAEB}}<S_{\mathrm{EACB}}$, the probability of both sides adopting cooperation strategy is higher than competition. The area of regions I and II is related to effort level, big data capability, distribution ratio, transferability of data, data stock, learning ability, and cost.

Since $S_{\mathrm{OAEB}}+S_{\mathrm{EACB}}=1$, the influence of the same parameter on the area of two regions is reversed, so only one of them need to be analyzed. Next, we analyse the influence of parameters on $S_{\mathrm{OAEB}}$ :

$$
S_{\mathrm{OAEB}}=\frac{1}{2}\left(\frac{c_{s}-Q_{s}\left(e_{s}^{\varphi}-1\right) T}{T\left(Q_{s} e_{s}^{\varphi}\left(\beta e_{r}^{\mu}-1\right)-Q_{r} e_{r}^{\mu}\left(x_{s}-e_{s}^{\varphi} \beta\right)\right)}+\frac{c_{r}-Q_{r}\left(e_{r}^{\mu}-1\right) T}{T\left(Q_{r} e_{r}^{\mu}\left(e_{s}^{\varphi}(1-\beta)-1\right)-Q_{s} e_{s}^{\varphi}\left(x_{r}-e_{r}^{\mu}(1-\beta)\right)\right)}\right) .
$$

In the process of cooperative game, the stability strategy of an enterprise is closely related to the change in various factors. The following analysis is carried out on the factors affecting the enterprise strategy. 


\subsection{Transferability of Big Data}

Theorem 2. For the transferability of data into knowledge, higher transferability makes a higher probability of firms choosing cooperation.

Proof. Take the derivative of $T$ with respect to $S_{\mathrm{OAEB}}$, and we can get $\left(\partial S_{\mathrm{I}} / \partial T\right)$ is less than 0 when everything else stays the same. $\quad\left(\partial S_{\mathrm{I}} / \partial T\right)=\left(1 / 2 T^{2}\right) \quad\left(\left(c_{r} / Q_{r} e_{r}^{\mu}+e_{s}^{\varphi}\left(Q_{s} x_{r}-\left(Q_{r}+\right.\right.\right.\right.$ $\left.\left.\left.\left.Q_{s}\right) e_{r}^{\mu}(1-\beta)\right)\right)+\left(c_{s} / Q_{r} e_{r}^{\mu} x_{s}+e_{s}^{\varphi}\left(Q_{s}-\left(Q_{r}+Q_{s}\right) e_{r}^{\mu} \beta\right)\right)\right)$, according to the assumptions of $c_{r}$ and $c_{s}$, we can get $Q_{r} e_{r}^{\mu}+$ $e_{s}^{\varphi}\left(Q_{s} x_{r}-\left(Q_{r}+Q_{s}\right) e_{r}^{\mu}(1-\beta)\right)<0$ and $Q_{r} e_{r}^{\mu} x_{s}+e_{s}^{\varphi}\left(Q_{s}-\right.$ $\left.\left(Q_{r}+Q_{s}\right) e_{r}^{\mu} \beta\right)<0$, so $\left(\partial S_{\mathrm{OAEB}} / \partial T\right)<0$, then $\left(\partial S_{\mathrm{OAEB}} / \partial T\right)>0$ This indicates that the higher the value density of big data owned by enterprises, the higher the data transferability and easier to cooperate with other firms. With the improvement in data utilization, enterprises are more willing to share data with partners and further analyse and process the data.

\subsection{Big Data Stock}

Theorem 3. For the big data stock, a higher stock makes a higher probability of firms choosing cooperation.

Proof. Same as before, take the derivative of $Q_{r}$ and $Q_{s}$ with respect to $S_{\mathrm{OAEB}}$, we can get $\left(\partial S_{\mathrm{I}} / \partial Q_{s}\right)<0\left(\partial S_{\mathrm{I}} / \partial Q_{r}\right)<0$ when everything else stays the same, so $\left(\partial S_{\mathrm{EACB}} / \partial Q_{s}\right)>0\left(\partial S_{\mathrm{EACB}} / \partial Q_{r}\right)>0$. It indicates that, with the increase in enterprise data stock, the probability of enterprise implementing cooperative strategy is greater. On the one hand, the more data an enterprise has, the more likely it is to acquire more knowledge. As data sharing activities between enterprises and partners continue to increase, their own data stock will also increase. Meanwhile, the higher data stock imposes higher costs of storing and analysing, and more enterprises are inclined to share through cooperation. Therefore, the accumulation of enterprise data stock and the implementation of cooperation strategy between enterprises are mutually reinforcing each other.

\subsection{Learning Capability}

Theorem 4. For the learning capability, there must be a critical value of learning capability that makes cooperation break down.

Proof. According to the first derivative, we can get $\left(\partial S_{\mathrm{I}} / \partial x_{s}\right)>0\left(\partial S_{\mathrm{I}} / \partial x_{r}\right)>0$ and $\left(\partial^{2} S_{\mathrm{I}} / \partial x_{s}^{2}\right)>0\left(\partial^{2} S_{\mathrm{I}} / \partial x_{r}^{2}\right)<0$. It means the probability of cooperation decreases strictly with the increase in both parties' learning capability. According to Theorem 1, when $x_{s}>\left(\beta\left(Q_{r}+Q_{s}\right) e_{s}^{\varphi}-\right.$ $\left.Q_{s} e_{s}^{\varphi} e_{r}^{-\mu} / Q_{r}\right)$ and $x_{r}>\left((1-\beta)\left(Q_{r}+Q_{s}\right) e_{r}^{\mu}-Q_{r} e_{r}^{\mu} e_{s}^{-\varphi} / Q_{s}\right)$, both sides choose to complete. Therefore, cooperation can only be realized when the learning capability of both parties is below the critical point, and the probability of cooperation increases with the decrease in learning capability. Knowledge spillovers in the process of cooperation will result in the loss of hidden knowledge income. With the increase in communication between enterprises and the improvement of learning ability of cooperative partners, the probability of knowledge theft will be further increased, the probability of knowledge loss will also increase, and the willingness of enterprises to cooperate will be reduced.

\subsection{Big Data Capability}

Theorem 5. For the big data capability, a higher capability makes a higher probability of firms choosing cooperation, and firms favor cooperation among peers with same capabilities.

Proof. Same as before, we can get $\left(\partial S_{\mathrm{I}} / \partial \varphi\right)<0$ and $\left(\partial S_{\mathrm{I}} / \partial \mu\right)<0$, so $\left(\partial S_{\mathrm{EACB}} / \partial \varphi\right)>0$ and $\left(\partial S_{\mathrm{EACB}} / \partial \mu\right)>0$. Therefore, the cooperation probability increases with the big data capability of both parties. The convexity of monotone function can be obtained by the second derivative. According to the first derivative, we can get the second derivative has an inflection point $\varphi^{*}$; when $\varphi<\varphi^{*},\left(\partial^{2} S_{\mathrm{II}} / \partial \varphi^{2}\right)>0$, and when $\varphi>\varphi^{*},\left(\partial^{2} S_{\mathrm{II}} / \partial \varphi^{2}\right)<0$. In addition, we take the derivative of $\mu$ with respect to $\partial S_{\mathrm{II}} / \partial \varphi$ and get $\left(\partial^{2} S_{\mathrm{I}} / \partial \varphi \partial \mu\right)<0$ is always true. So we get the graph of $\mathrm{S}_{\mathrm{EACB}}$ with respect to $\varphi$ and $\mu$, as shown in Figure 5 .

When the big data capability of firm $\mathrm{S}$ is stronger and the big data capability of the other party is weaker, the probability of cooperation between the two parties is higher (i.e., the circle node in Figure 5). This is because when the firm has a stronger ability, the other party is more willing to cooperate with it. The more confident the firm is about the probability of the other party choosing to cooperate, the higher confidence guarantees to be favorable to cooperation. When the enterprise has a weaker ability, the more difficult it is to ensure the other party is willing to cooperate. Similarly, enterprise $R$ expects such a situation. Both sides expect high data capability, but big data capability is the elasticity coefficient of efforts, which is between 0 and 1 . After repeated games, both companies tend to be in the middle. In addition, when one's own capability is weak and the other's capability is also weak, it is easy to reach cooperation (i.e., the square node in Figure 5). When each firm's data capability is strong, it is also easy to reach cooperation (i.e., the strong union). This is because both sides data capability are comparable to their partners and more willing to cooperate. That is, firms with similar capabilities are more willing to cooperate.

\subsection{Optimal Distribution Coefficient}

Theorem 6. Keeping other factors unchanged, there is an optimal distribution coefficient $\beta$ that maximizes the probability of both enterprises adopting cooperative strategies. 

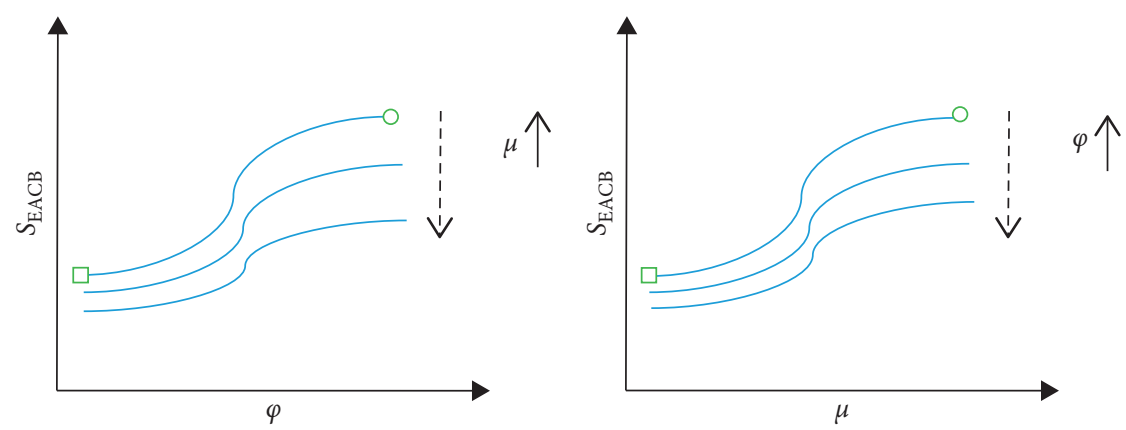

FIGURE 5: The relationship between cooperative area and big data capacity.

Proof. According to the first derivative,

$$
\frac{\partial S_{I}}{\partial x_{s}}=\frac{\left(Q_{r}+Q_{s}\right) e_{r}^{\mu} e_{s}^{\varphi}}{2 T}\left(\frac{c_{r}-Q_{r}\left(e_{r}^{\mu}-1\right) T}{\left(Q_{s} e_{s}^{\varphi}\left(x_{r}-e_{r}^{\mu}(1-\beta)\right)+Q_{r} e_{r}^{\mu}\left(1-e_{s}^{\varphi}(1-\beta)\right)\right)^{2}}-\frac{c_{s}-Q_{s}\left(e_{s}^{\varphi}-1\right) T}{\left(Q_{s} e_{s}^{\varphi}\left(e_{r}^{\mu} \beta-1\right)-Q_{r} R^{\mu}\left(x_{s}-e_{s}^{\varphi} \beta\right)\right)^{2}}\right) .
$$

So, cooperative probability $S$ is not a monotonic function of distribution coefficient $\beta$. Then, we can get the second derivative $\left(\partial^{2} S_{\mathrm{I}} / \partial \varphi^{2}\right)>0$ is always true. This means there must be a minimum value for $S_{\mathrm{I}}$, where the cooperative region has a maximum value. We can get the optimal distribution coefficient $\beta^{*}$ by solving the equation $\left(\partial S_{\mathrm{I}} / \partial x_{s}\right)=0$. When $\beta=\beta^{*}$, the probability of firms' cooperative innovation strategy converging to $C$ is the largest.

Theorem 7. The distribution coefficient is positively correlated with firm's capability to learn big data knowledge from rivals; that is, stronger learning capability makes higher distribution coefficient.

Proof. According to the first derivative, we get $\left(\partial \beta^{*} / \partial x_{s}\right)>0\left(\partial \beta^{*} / \partial x_{r}\right)>0$. It can be found that the distribution coefficient is an increasing function of the firm's learning capability, and the stronger the firm's learning capability is, the higher the income distribution ratio it obtains. This is because in the cooperative innovation process of firms, the stronger the learning ability is, the more likely the betrayal will be. The other party can only ensure the non-betrayal of the partner by improving the income distribution of payment, but when the learning ability exceeds the critical value, neither party will choose to cooperate.

According to the model results, big data affects the cooperative innovation behavior of enterprises from two aspects:

(1) The basic characteristics of big data have a positive impact on the cooperative behavior. If participants shared data have high value density and stock, the stronger the willingness of the other party to participate in the cooperation, the more the cooperation process tends to be stable and effective. In this sense, the results suggest that it is easier to achieve cooperation in the big data environment. This cooperative process is more effective since it allows to make decisions related to the characteristics of the new product on massive data and not only on the experience of the actors participating, and this considerably reduces the risk associated with the lack of acceptance of the products by the end customer. The efficiency of data access and use has a direct relationship with the outcomes of the cooperative process since it can facilitate or hinder collaborative work.

(2) The big data ability has two-sided influence on the cooperative behavior. We found that similar big data capabilities will enhance the firm's willingness to cooperate and partners' higher learning ability will reduce firm's cooperative willingness. An implication of this finding is that enterprise should have absorptive capacity to be able to benefit from cooperative innovation, and cooperation should be conducted with enterprises of the similar level of ability to avoid opportunistic behavior. This result is in line with an organizational learning perspective which focuses on absorptive capacity as the main determinant of firms' competitive advantages. In other words, similar ability could strengthen the cooperative willingness of both sides. In addition, the model results confirm that enterprises' investment in intangible and tangible resources involved in big data capabilities has a negative impact on their willingness to cooperate.

\section{Results Verification}

Having analyzed the models, the researchers revisited $\mathrm{S}$ to verify the results. The CEO of $S$ is very supportive of the findings. Far too often, $\mathrm{S}$ been struggled to decide on how best to choose suitable partners for cooperation or making 

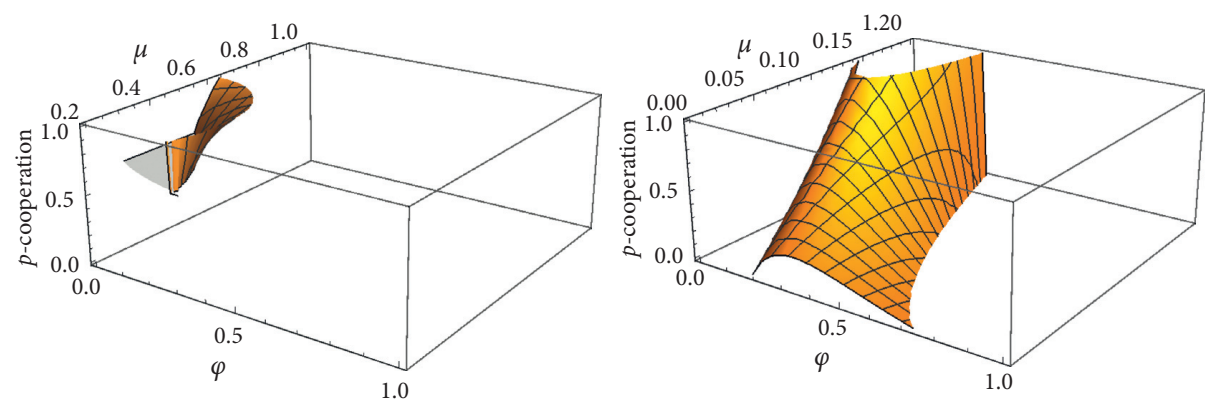

Figure 6: The influence of big data capability.

decisions to move forward. The findings gained from the model provided S with confidence and a basis for making the right decisions.

The problems faced by enterprise $S$ are as follows: (1) it has invested in some big data construction, but its big data analysis ability is weak; (2) its learning and absorption ability is at the average level of the industry; (3) it hopes to make up for some of the previous big data investment through cooperation, and the proportion of revenue sharing should not be higher than $60 \%$.

According to the data of $\mathrm{S}$ and relevant model assumptions, we will verify the results obtained by model analysis in this section. The numerical setting is reduced equably according to the actual situation of the enterprise and rounded to the value. Since firm S belongs to the computer hardware industry, big data technology greatly improves innovation. Considering the sales volume of $S$ and its upstream manufacturers' innovative products in the first year, we set at $T=4$.

7.1. For the Big Data Capability. Since there is a critical value of learning capability, $x_{s}=0.3$ and $x_{r}=0.3$ are set according to the condition of the equilibrium solution. Given the $Q_{s}=8, Q_{r}=4, c_{s}=41$, and $c_{r}=45$. The effort made by both sides for cooperation is $e_{s}=20$ and $e_{r}=25$. Given $\beta=0.4$. Matlab is used to draw the influence of big data capability on the probability of cooperation area (Figure 6).

It can be seen from the figure that when the data capacity of the partner is higher than 0.2 , the cooperation probability of both sides can maintain a high level, and the closer big data capacity of both sides can maintain a higher probability of cooperation. This is consistent with the conclusion of Theorem 5 . When the big data capacity of the partner is very low, S will choose not to cooperate and the probability of cooperation decreases with the greater gap between the two sides. In addition, we can find that the cooperation area between the two parties is small, especially when the cooperation partner has a higher capacity, and the area is significantly reduced. Since both parties are SMEs, the critical point of cooperation is small (e.g., 0.2). If both parties are large enterprises, their cost, stock, and other data will be higher, and the critical point may increase. In the actual situation, firm $S$ tried to negotiate with three enterprises and finally reached an agreement with the partner whose data capacity was basically in line with S (in terms of data stock, data analysis of human resources and data validity).

7.2. For the Learning Capability. Set the parameters to $e_{s}=20, e_{r}=25, \varphi=0.3$, and $\mu=0.4$. Given the $\beta=0.4$. We can get the influence of learning capability on the probability of cooperation area.

Figure 7 shows that there is a critical point in firm S's learning ability. When firm S's learning capability is too high, cooperation cannot be reached. However, in the feasible region, the cooperation probability is very high and decreases with the increase in the learning capability of the other parties (but the change is very small), which is consistent with the conclusion of Theorem 4 . In addition, we can see that $x_{r}$ can approach 1 because the $x_{r}$ expression given in Theorem 4 is higher than 1 in this case. For firm S, its own weakness lies in its low big data capability, so it needs to cooperate with other partners. Therefore, no matter what level of learning capability the partner has, the knowledge that can be stolen from $S$ is limited, and the best can only be achieved through the efforts of both parties. The critical value of firm $S$ is due to the uncertainty of the partner. If firm $S$ has too strong learning ability, the other party will not choose to cooperate.

7.3. For the Distribution Coefficient. According to the above analysis, we set the parameters to $e_{s}=20, e_{r}=25, \varphi=0.3$, $\mu=0.4, x_{s}=0.3$, and $x_{r}=0.3$. We can get the influence of distribution coefficient on the probability of cooperation area (Figure 8).

We can see that there is an optimal allocation ratio to maximize the cooperation probability, which is consistent with the conclusion of Theorem 6 . When the distribution coefficient is higher than 0.8 , cooperation cannot be reached, and when the cooperation probability is slightly lower than 0.8 , it obviously increases. When the distribution coefficient approaches 0.6 , the cooperation probability is the highest, which is also the negotiation space for firm $S$ to negotiate with other firms.

In light of enterprises $S$ encountered problems, we can give the following suggestions:

(1) Due to the high barriers entry, the absorption capacity of SME in the industry is generally lower, so the partner selection should consider the learning 


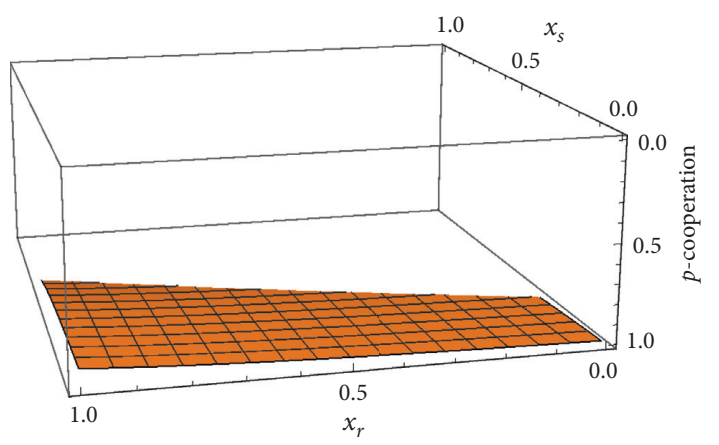

Figure 7: The influence of learning capability.

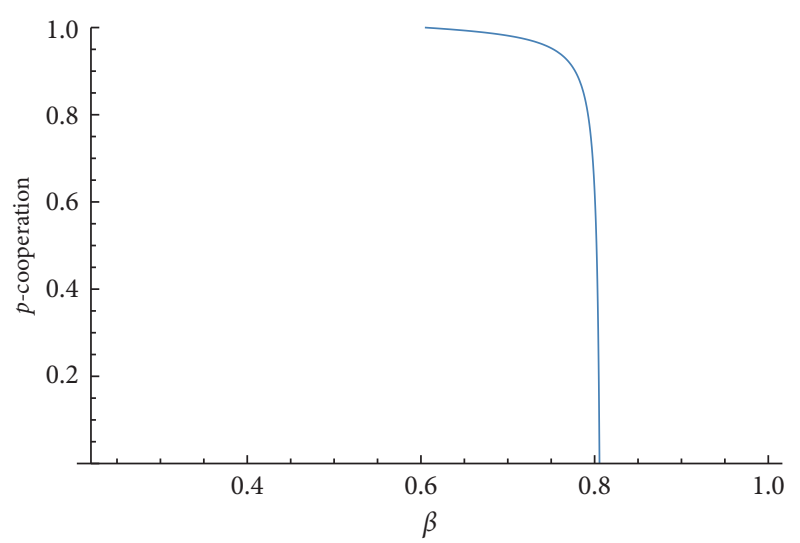

Figure 8: The change in distribution coefficient.

ability cannot be higher than themselves; that is, the cooperative enterprise's technical personnel shall be flat with the company.

(2) Because $S$ has invested in big data, it has a certain amount of data, and the data stock can be used as a cooperation advantage, so it can gain certain dominance in the profit sharing negotiation. Data complementarity should be considered when selecting partners.

(3) Considering the stability of cooperation and its own weak big data capability, the selected partner's big data capability can be slightly higher than its own.

(4) Enterprise S has a limited budget for cooperative investment, so it may invest less efforts in the cooperation than the partner. Therefore, it can make some concessions in profit sharing to encourage the partner to increase investment.

\section{Conclusions}

8.1. Value of Research. Data resources have become an important competitive factor for firms in the era of digital economy. With the development of high technology, enterprises can have frequent contact with consumers through a variety of channels, so as to have a deeper understanding of market demand and a better understanding of consumer behavior. The data age has made it easier for companies to use "big data" to accelerate product/service innovation. However, the shortcomings of big data capabilities in firms cannot be ignored (such as high cost of data storage, insufficient data mining capability, and silo data, etc.) as it may lead to unsuccessful product innovation. In other words, firms do not innovate in isolation, at least not in an effective way. Therefore, cooperative innovation is vital for firms to sustain development and gain competitiveness.

On the other hand, the success rate of cooperative innovation is not high. No matter whether there is market competition between partners, data sharing makes firm lose its unique right to data, and partners' opportunism will cause great losses to the sharing party. Cooperative innovation entails the dualism of competition and cooperation; i.e., the cooperative relationship tends to break down easily as the spirit of fighting alone is still common in firms. Hence, big data adoption and cooperation are vital for firms to sustain competitive advantages. Specifically, the combination of big data and advanced analytics techniques (i.e., data mining and machine learning) has big implication on innovation cooperation behaviors among firms.

This paper adopted a mixed method approach (case study-modelling-case study) to study firms' co-opetition behavior based on their data analytics capabilities for innovation. Our study suggests a number of very important implications for managers of SMEs. One of the most important implications is that firms favor cooperation among peers with similar capabilities; i.e., when each firm's data level is comparable to their partners. According to our results, similar big data capabilities will enhance the firm's willingness to cooperate, managers should also focus on enhancing their internal capabilities such as big data capabilities and absorptive capacity. Absorptive capacity enables firms to capitalize on acquired knowledge. Firms with high levels of absorptive capacity are more capable of utilizing the acquired data knowledge to improve innovation performance. Cooperation should be conducted with enterprises of the similar level of ability to maintain the stability of cooperation. Therefore, to be able to effectively develop collaboration on innovation, managers should simultaneously develop collaboration with similar ability level actors and improve their own capacity.

According to our results, the basic characteristics of big data have a positive impact on the cooperative behavior. Big data environment increases the possibility of cooperation. Decisions based on massive amounts of data and high-value data are more efficient, which improves the performance of collaborative innovation. The efficiency of data access and use has a direct relationship with the outcomes of the cooperative process since it can facilitate or hinder collaborative work. On the other hand, managers should control investment costs. Enterprises can make full use of the complementary advantages of resources in the process of cooperation and make use of the data resources of the other party to reduce the input cost of big data in the innovation process.

Moreover, our study demonstrates that the decisions of participants must be the same. We explain the evolution path of firms' cooperation decisions and discuss the best 
options for them to sustain long-term growth and competitiveness. One firm chooses cooperation, and the others choose competition is in an unstable state; that is, the result of system evolution is that both choose cooperation or both choose competition. Firms can find the optimal distribution ratio through negotiation and reach the final cooperation. Finally, we give some suggestions based on the situation of enterprises $\mathrm{S}$, and it can also provide reference for SMEs in the same industry.

8.2. Limitations and Future Directions. Big data brings new and exciting opportunities and uncertainties for firms. However, staying competitive will require firms to change their innovation strategies. Even though some of the discussed trends is still at the role of big data in the innovation process, this paper offers a few insights for the future.

We have demonstrated how the big data capability and process can facilitate the cooperative innovation between firms. However, the capability analysis was mainly based on one parameter. Thus, a much wider detailed factor analysis of the big data analysis is needed to do. Moreover, different industries will have different challenges in dealing with big data. Thus, future research can investigate what other big data capacities are available for manufacturing firms to sustain competitive advantages.

\section{Data Availability}

The model verification data used to support the findings of this study are included within the article.

\section{Conflicts of Interest}

The authors declare that there are no conflicts of interest regarding the publication of this paper.

\section{Acknowledgments}

This research was supported by the National Natural Science Foundation of China (NSFC) (Project nos. 71571151, 71871197, and 71872158).

\section{References}

[1] P. Ghemawat, "Finding your strategy in the new landscape," Harvard Business Review, vol. 88, no. 3, pp. 54-60, 2010.

[2] P. Hilletofth, D. Ericsson, and K. Lumsden, "Coordinating new product development and supply chain management," International Journal of Value Chain Management, vol. 4, no. 2, pp. 170-192, 2010.

[3] K. Prashant and S. Harbir, "Managing strategic alliances: what do we know now, and where do we go from here?" Academy of Management Perspectives, vol. 23, no. 3, pp. 45-62, 2009.

[4] P. Del Vecchio, A. Di Minin, A. M. Petruzzelli, U. Panniello, and S. Pirri, "Big data for open innovation in SMEs and large corporations: trends, opportunities, and challenges," Creativity and Innovation Management, vol. 27, no. 1, pp. 6-22, 2018.

[5] M. B. Uddin and B. A. Lecturer, "Strategic alliance and competitiveness: theoretical framework," Journal of Arts, Science \& Commerce, II, vol. 1, pp. 44-54, 2011.
[6] S. Heidenreich and T. Kraemer, "Innovations-Doomed to fail? Investigating strategies to overcome passive innovation resistance," Journal of Product Innovation Management, vol. 33, no. 3, pp. 277-297, 2016.

[7] D. Luzzini, M. Amann, F. Caniato, M. Essig, and S. Ronchi, "The path of innovation: purchasing and supplier involvement into new product development," Industrial Marketing Management, vol. 47, pp. 109-120, 2015.

[8] A. S. Alexiev, H. W. Volberda, and F. A. J. Van den Bosch, "Interorganizational collaboration and firm innovativeness: unpacking the role of the organizational environment," Journal of Business Research, vol. 69, no. 2, pp. 974-984, 2016.

[9] N. Heirati, A. O'Cass, K. Schoefer, and V. Siahtiri, "Do professional service firms benefit from customer and supplier collaborations in competitive, turbulent environments?" Industrial Marketing Management, vol. 55, pp. 50-58, 2016.

[10] T. Clauss and T. Kesting, "How businesses should govern knowledge-intensive collaborations with universities: an empirical investigation of university professors," Industrial Marketing Management, vol. 62, pp. 185-198, 2017.

[11] N. Amara and R. Landry, "Sources of information as determinants of novelty of innovation in manufacturing firms: evidence from the 1999 statistics Canada innovation survey," Technovation, vol. 25, no. 3, pp. 245-259, 2005.

[12] K.-H. Tsai, "Collaborative networks and product innovation performance: toward a contingency perspective," Research Policy, vol. 38, no. 5, pp. 765-778, 2009.

[13] N. Tzokas, Y. A. Kim, H. Akbar, and H. Al-Dajani, "Absorptive capacity and performance: the role of customer relationship and technological capabilities in high-tech SMEs," Industrial Marketing Management, vol. 47, pp. 134-142, 2015.

[14] G. Wang, A. Gunasekaran, E. W. T. Ngai, and T. Papadopoulos, "Big data analytics in logistics and supply chain management: certain investigations for research and applications," International Journal of Production Economics, vol. 176, no. June, pp. 98-110, 2016.

[15] P. Akhtar, Y. K. Tse, Z. Khan, and R. Rao-Nicholson, "Datadriven and adaptive leadership contributing to sustainability: global agri-food supply chains connected with emerging markets," International Journal of Production Economics, vol. 181, pp. 392-401, 2016.

[16] S. Fosso Wamba, A. Gunasekaran, T. Papadopoulos, and E. Ngai, "Big data analytics in logistics and supply chain management," The International Journal of Logistics Management, vol. 29, no. 2, pp. 478-484, 2018.

[17] M. M. Gobble, "Big data: the next big thing in innovation," Research-Technology Management, vol. 56, no. 1, pp. 64-67, 2013.

[18] T. H. Davenport, Big Data at Work: Dispelling the Myths, Uncovering the Opportunities, Harvard Business Review Press, Brighton, MA, USA, 2014.

[19] S. Kaisler, A. Frank, J. Alberto Espinosa et al., "Big data: issues and challenges moving forward," in Proceedings of the 46th Hawaii International Conference on System Sciences, IEEE, Wailea, HI, USA, January 2013.

[20] G. Secundo, P. Del Vecchio, G. Schiuma, and G. Passiante, "Activating entrepreneurial learning processes for transforming university students' idea into entrepreneurial practices," International Journal of Entrepreneurial Behavior \& Research, vol. 23, no. 3, pp. 465-485, 2017.

[21] A. Gandomi and M. Haider, "Beyond the hype: big data concepts, methods, and analytics," International Journal of Information Management, vol. 35, no. 2, pp. 137-144, 2015.

[22] K. H. Tan, Y. Zhan, G. Ji, F. Ye, and C. Chang, "Harvesting big data to enhance supply chain innovation capabilities: an 
analytic infrastructure based on deduction graph," International Journal of Production Economics, vol. 165, pp. 223-233, 2015.

[23] P. Fader, Customer Centricity: Focus on the Right Customers for Strategic Advantage, Wharton Digital Press, Philadelphia, PA, USA, 2nd edition, 2012.

[24] K. H. Tan, G. Ji, C. P. Lim, and M.-L. Tseng, "Using big data to make better decisions in the digital economy," International Journal of Production Research, vol. 55, no. 17, pp. 4998-5000, 2017.

[25] J. S. Ward and A. Barker, "Undefined by data: a survey of big data definitions," Computer Science, http://arxiv.org/abs/ 1309.5821, 2013.

[26] K. N. Singh and Y. Shetty, "Data sharing: a viable resource for future," Perspectives in Clinical Research, vol. 8, no. 2, pp. 63-67, 2017.

[27] M. Sakakibara, "Knowledge sharing in cooperative research and development," Managerial and Decision Economics, vol. 24, no. 2-3, pp. 117-132, 2003.

[28] R. Bergmann and G. Friedl, "Controlling innovative projects with moral hazard and asymmetric information," Research Policy, vol. 37, no. 9, pp. 1504-1514, 2008.

[29] K. Kalaignanam, V. Shankar, and R. Varadarajan, "Asymmetric new product development alliances: win-win or winlose partnerships?" Management Science, vol. 53, no. 3, pp. 357-374, 2007.

[30] M. Levy, C. Loebbecke, and P. Powell, "SMEs, co-opetition and knowledge sharing: the role of information systems," European Journal of Information Systems, vol. 12, no. 1, pp. 3-17, 2003.

[31] X. Jin, B. W. Wah, X. Cheng, and Y. Wang, "Significance and challenges of big data research," Big Data Research, vol. 2, no. 2, pp. 59-64, 2015.

[32] I. Yaqoob, I. A. T. Hashem, A. Gani et al., "Big data: from beginning to future," International Journal of Information Management, vol. 36, no. 6, pp. 1231-1247, 2016.

[33] M. Ghasemaghaei, "Does data analytics use improve firm decision making quality? The role of knowledge sharing and data analytics competency," Decision Support Systems, vol. 120, pp. 14-24, 2019.

[34] J. S. Johnson, S. B. Friend, and H. S. Lee, "Big data facilitation, utilization, and monetization: exploring the $3 \mathrm{Vs}$ in a new product development process," Journal of Product Innovation Management, vol. 34, no. 5, pp. 640-658, 2017.

[35] M. Ghasemaghaei and G. Calic, "Assessing the impact of big data on firm innovation performance: big data is not always better data," Journal of Business Research, vol. 108, pp. 147$162,2020$.

[36] S. Erevelles, N. Fukawa, and L. Swayne, "Big Data consumer analytics and the transformation of marketing," Journal of Business Research, vol. 69, no. 2, pp. 897-904, 2016.

[37] K. H. Tan, "Managerial perspectives of big data analytics capability towards product innovation," Strategic Direction, vol. 34, no. 8, pp. 33-35, 2018.

[38] M. Gupta and J. F. George, "Toward the development of a big data analytics capability," Information \& Management, vol. 53, no. 8, pp. 1049-1064, 2016.

[39] G. George, E. C. Osinga, D. Lavie, and B. A. Scott, "Big data and data science methods for management research," Academy of Management Journal, vol. 59, no. 5, pp. 14931507, 2016.

[40] S. F. Wamba, A. Gunasekaran, S. Akter, S. J.-F. Ren, R. Dubey, and S. J. Childe, "Big data analytics and firm performance: effects of dynamic capabilities," Journal of Business Research, vol. 70, pp. 356-365, 2017.

[41] W. Chen, T. Niebel, and M. Saam, "Are intangibles more productive in ICT-intensive industries? Evidence from EU countries," Telecommunications Policy, vol. 40, no. 5, pp. 471-484, 2016.

[42] T. Niebel, F. Rasel, and S. Viete, "BIG data-BIG gains? Understanding the link between big data analytics and innovation," Economics of Innovation and New Technology, vol. 28, no. 3, pp. 296-316, 2019.

[43] E. Brynjolfsson and K. McElheran, "The rapid adoption of Data-Driven Decision-Making," American Economic Review, vol. 106, no. 5, pp. 133-139, 2016.

[44] N. Bloom, R. Sadun, and J. V. Reenen, "Americans do IT better: US multinationals and the productivity miracle," American Economic Review, vol. 102, no. 1, pp. 167-201, 2012.

[45] C. Corrado, J. Haskel, and C. Jona-Lasinio, "Knowledge spillovers, ICT and productivity growth," Oxford Bulletin of Economics and Statistics, vol. 79, no. 4, pp. 592-618, 2017.

[46] S. Najafi-Tavani, Z. Najafi-Tavani, P. Naudé, P. Oghazi, and E. Zeynaloo, "How collaborative innovation networks affect new product performance: product innovation capability, process innovation capability, and absorptive capacity," Industrial Marketing Management, vol. 73, pp. 193-205, 2018.

[47] B. Weber and S. Heidenreich, "When and with whom to cooperate? Investigating effects of cooperation stage and type on innovation capabilities and success," Long Range Planning, vol. 51, no. 2, pp. 334-350, 2018.

[48] S. M. Lee, T. Hwang, and D. Choi, "Open innovation in the public sector of leading countries," Management Decision, vol. 50, no. 1, pp. 147-162, 2012.

[49] P. R. Tomlinson, "Co-operative ties and innovation: some new evidence for UK manufacturing," Research Policy, vol. 39, no. 6, pp. 762-775, 2010.

[50] T. Clauß and P. Spieth, "Treat your suppliers right! Aligning strategic innovation orientation in captive supplier relationships with relational and transactional governance mechanisms," R\&D Management, vol. 46, no. S3, pp. 1044-1061, 2016.

[51] D. R. Krause, R. B. Handfield, and B. B. Tyler, "The relationships between supplier development, commitment, social capital accumulation and performance improvement," Journal of Operations Management, vol. 25, no. 2, pp. 528-545, 2007.

[52] T.-J. A. Peng, S. Pike, J. C.-H. Yang, and G. Roos, "Is cooperation with competitors a good idea? An example in practice," British Journal of Management, vol. 23, no. 4, pp. 532-560, 2012.

[53] X. Luo, R. J. Slotegraaf, and X. Pan, "Cross-functional "coopetition": the simultaneous role of cooperation and competition within firms," Journal of Marketing, vol. 70, no. 2, pp. $67-80,2006$.

[54] R. B. Bouncken and S. Kraus, "Innovation in knowledgeintensive industries: the double-edged sword of coopetition," Journal of Business Research, vol. 66, no. 10, pp. 2060-2070, 2013.

[55] R. B. Bouncken and V. Fredrich, "Coopetition: performance implications and management antecedents," International Journal of Innovation Management, vol. 16, no. 5, Article ID 1250028, 2012.

[56] B. Bozeman, "Technology transfer and public policy: a review of research and theory," Research Policy, vol. 29, no. 4-5, pp. 627-655, 2000. 
[57] O. Vuola and A.-P. Hameri, "Mutually benefiting joint innovation process between industry and big-science," Technovation, vol. 26, no. 1, pp. 3-12, 2006.

[58] J. J. Reuer and M. Zollo, "Termination outcomes of research alliances," Research Policy, vol. 34, no. 1, pp. 101-115, 2005.

[59] A.-P. de Man and G. Duysters, "Collaboration and innovation: a review of the effects of mergers, acquisitions and alliances on innovation," Technovation, vol. 25, no. 12, pp. 1377-1387, 2005.

[60] H. Li, J. Zhang, C. Wang, Y. Wang, and V. Coffey, "An evaluation of the impact of environmental regulation on the efficiency of technology innovation using the combined DEA model: a case study of Xi'an, China," Sustainable Cities and Society, vol. 42, pp. 355-369, 2018.

[61] Z. Ge, Q. Hu, and Y. Xia, "Firms' R\&D cooperation behavior in a supply chain," Production and Operations Management, vol. 23, no. 4, pp. 599-609, 2014.

[62] S. Wang and F. Liu, "Cooperative innovation in a supply chain with different market power structures," American Journal of Operations Research, vol. 06, no. 02, pp. 173-198, 2016.

[63] R.-J. B. Jean, R. R. Sinkovics, and T. P. Hiebaum, "The effects of supplier involvement and knowledge protection on product innovation in customer-supplier relationships: a study of global automotive suppliers in China," Journal of Product Innovation Management, vol. 31, no. 1, pp. 98-113, 2014.

[64] A. K. W. Lau, "Supplier and customer involvement on new product performance: contextual factors and an empirical test from manufacturer perspective," Industrial Management \& Data Systems, vol. 111, no. 5-6, pp. 910-942, 2011.

[65] K. Abdolmaleki and S. Ahmadian, "The relationship between product characteristics, customer and supplier involvement and new product development," Procedia Economics and Finance, vol. 36, pp. 147-156, 2016.

[66] W. Chang and S. A. Taylor, "The effectiveness of customer participation in new product development: a meta-analysis," Journal of Marketing, vol. 80, no. 1, pp. 47-64, 2016.

[67] W. Wang and Y. Liu, "Investigation into operation mechanism of university-enterprise cooperative innovation network: taking Henan province as example," Technology Economics, vol. 33, no. 2, pp. 134-149, 2011.

[68] A. Wu, Z. Wang, and S. Chen, "Impact of specific investments, governance mechanisms and behaviors on the performance of cooperative innovation projects," International Journal of Project Management, vol. 35, no. 3, pp. 504-515, 2017.

[69] P. M. Bosch-Sijtsema and T. J. B. M. Postma, "Cooperative innovation projects: capabilities and governance mechanisms," Journal of Product Innovation Management, vol. 26, no. 1, pp. 58-70, 2009.

[70] D. R. Gnyawali and B.-J. Park, "Co-opetition and technological innovation in small and Medium-Sized enterprises: a multilevel conceptual model," Journal of Small Business Management, vol. 47, no. 3, pp. 308-330, 2009.

[71] A.-L. Mention, "Co-operation and co-opetition as open innovation practices in the service sector: which influence on innovation novelty?" Technovation, vol. 31, no. 1, pp. 44-53, 2011.

[72] J. Van den Broek, P. Boselie, and J. Paauwe, "Cooperative innovation through a talent management pool: a qualitative study on coopetition in healthcare," European Management Journal, vol. 36, no. 1, pp. 135-144, 2018.

[73] C. Capuano and I. Grassi, "Spillovers, product innovation and R\&D cooperation: a theoretical model," Economics of Innovation and New Technology, vol. 28, no. 2, pp. 197-216, 2019.
[74] D. B. Audretsch and M. Belitski, "The role of R\&D and knowledge spillovers in innovation and productivity," $E \mathbf{U}$ ropean Economic Review, vol. 123, Article ID 103391, 2020.

[75] W. M. Cohen and D. A. Levinthal, "Innovation and learning: the two faces of R \& D," The Economic Journal, vol. 99, no. 397, pp. 569-596, 1989.

[76] S. A. Zahra and G. George, "Absorptive capacity: a review, conceptualization and extension," Academy of Management Review, vol. 27, pp. 85-203, 2002.

[77] M. Bogers and S. Lhuillery, "A functional perspective on learning and innovation: investigating the organization of absorptive capacity," Industry \& Innovation, vol. 18, no. 6, pp. 581-610, 2011.

[78] S. Shim, B. Lee, and S. L. Kim, "Rival precedence and open platform adion: an empirical analysis," International Journal of Information Management, vol. 38, no. 1, pp. 217-231, 2018.

[79] R. Lin, Z. Xie, Y. Hao, and J. Wang, "Improving high-tech enterprise innovation in big data environment: a combinative view of internal and external governance," International Journal of Information Management, vol. 50, pp. 575-585, 2020.

[80] L. Aldieri, T. Makkonen, and C. Paolo Vinci, "Spoils of innovation? Employment effects of $\mathrm{R} \& \mathrm{D}$ and knowledge spillovers in Finland," Economics of Innovation and New Technology, pp. 1-15, 2019.

[81] H. W. Chesbrough, "The era of open innovation," MIT Sloan Management Review, vol. 44, no. 3, pp. 35-41, 2003.

[82] N. Rosenbusch, J. Brinckmann, and A. Bausch, "Is innovation always beneficial? A meta-analysis of the relationship between innovation and performance in SMEs," Journal of Business Venturing, vol. 26, no. 4, pp. 441-457, 2011.

[83] A. Arora, S. Athreye, and C. Huang, "The paradox of openness revisited: collaborative innovation and patenting by UK innovators," Research Policy, vol. 45, no. 7, pp. 1352-1361, 2016.

[84] M. Belitski, A. Aginskaja, and R. Marozau, "Commercializing university research in transition economies: technology transfer offices or direct industrial funding?" Research Policy, vol. 48, no. 3, pp. 601-615, 2019.

[85] M. Anshari, Y. Alas, and L. S. Guan, "Developing online learning resources: big data, social networks, and cloud computing to support pervasive knowledge," Education and Information Technologies, vol. 21, no. 6, pp. 1663-1677, 2016.

[86] M. Bogers, "The open innovation paradox: knowledge sharing and protection in R\&D collaborations," European Journal of Innovation Management, vol. 14, no. 1, pp. 93-117, 2011.

[87] B. J. Nalebuff and A. N. Brandenburger, Co-Opetition, Harper Collins, London, UK, 1996.

[88] W. Meeusen and J. Van den Broeck, "Efficiency estimation from cobb-douglas production functions with composed error," International Economic Review, vol. 18, no. 2, pp. 435-444, 1977.

[89] D. Friedman, "Evolutionary games in economics," Econometrica, vol. 59, no. 3, pp. 637-666, 1991. 